\title{
La réaction d'immunité cellulaire (capsule hémocytaire) chez un insecte, en fonction de la région du corps
}

\author{
par Y. CARTON \\ Laboratoire de Génétique évolutive, C.N.R.S., F 91190 Gif-sur-Yvette
}

Chez les insectes, la réaction d'immunité cellulaire se traduit le plus souvent par la formation d'une capsule hémocytaire autour du corps étranger. Cette capsule (quecertains nomment aussi granulome simple) est formée par le dépôt des hémocytes en plusieurs couches régulières qui s'organisent en 3 zones concentriques (François, 1975 ; Salt, 1970). Ce type de capsule est celui qui est le plus souvent rencontré en pathologie des insectes. Cependant, chez certaines espèces, la réaction hémocytaire ne se traduit pas par la formation d'une capsule aussi homogène : dans ce cas, les capsules sont représentées par des agrégats cellulaires plus ou moins volumineux, aux contours très irréguliers (Salt, 1954). C'est ce type de capsule que l'on rencontre chez la chrysalide diapausante de Pieris brassicae. Après avoir envisagé les aspects morphologiques d'une telleréaction, nous avons cherché à connaître si, d'une région à l'autre de la chrysalide, les réactions hémocytaires étaient comparables ou si au contraire, elles étaient d'intensité variable.

Matériel et méthodes.

Les chrysalides de Pieris brassicae en diapause, âgées de 10 à 15 jours, reçoivent un implant au niveau de l'une des régions suivantes (température : 20 ${ }^{\circ}$ ) :

$-1^{\mathrm{er}}-2^{\mathrm{e}}$ segments thoraciques ;

$-2^{e}-3^{e}$ segments abdominaux ;

$-8^{\circ}-9^{\circ}$ segments abdominaux.

Cet implant est représenté par un fragment stérile de nylon de $150 \mu$ de diamètre. Après 2 jours, 4 jours ou 8 jours, on dissèque la chrysalide pour récupérer l'implant enrobé de la capsule hémocytaire. Nous avons choisi de mesurer par planimétrie sur photo la surface de cette capsule (CARTON, 1975). 


\section{Résultats.}

A) Aspects morphologiques de la capsule hémocytaire.

L'aspect hétérogène de la capsule provient de la diversité des cellules qui la constituent. Dans le cas général évoqué ci-dessus, les auteurs s'accordent pour admettre que seuls les granulocytes et/ou les plasmatocytes participent à la formation de la capsule (Brehelin et al., 1975 ; François, 1975 ; Salt, 1970). Dans le cas de la chrysalide de Pieris, des adipohoemocytes, reconnaissables par la présence d'inclusions lipidiques très réfringentes sont incorporés à la capsule. De telles cellules, au moment de la métamorphose, sont très nombreuses et proviennent de la dissociation cellulaire du corps gras (Snodgrass, 1935). D'autre part, les adipohoemocytes, du moins en culture, présentent une nette tendance à se réagréger en présence de plasmatocytes (Walters, 1968). On conçoit aisément que les adipohoemocytes, libres dans l'hémolymphe de la chrysalide, participent à l'élaboration de la capsule hémocytaire.

B) Dynamique de la réaction en fonction des régions du corps.

Les résultats sont exprimés sur la figure 1. Dès le deuxième jour, on peut noter une différence d'intensité réactionnelle aux trois sites d'implantation choisis. Au quatrième jour, la réaction hémocytaire s'est amplifiée dans les trois cas. Toutefois, la

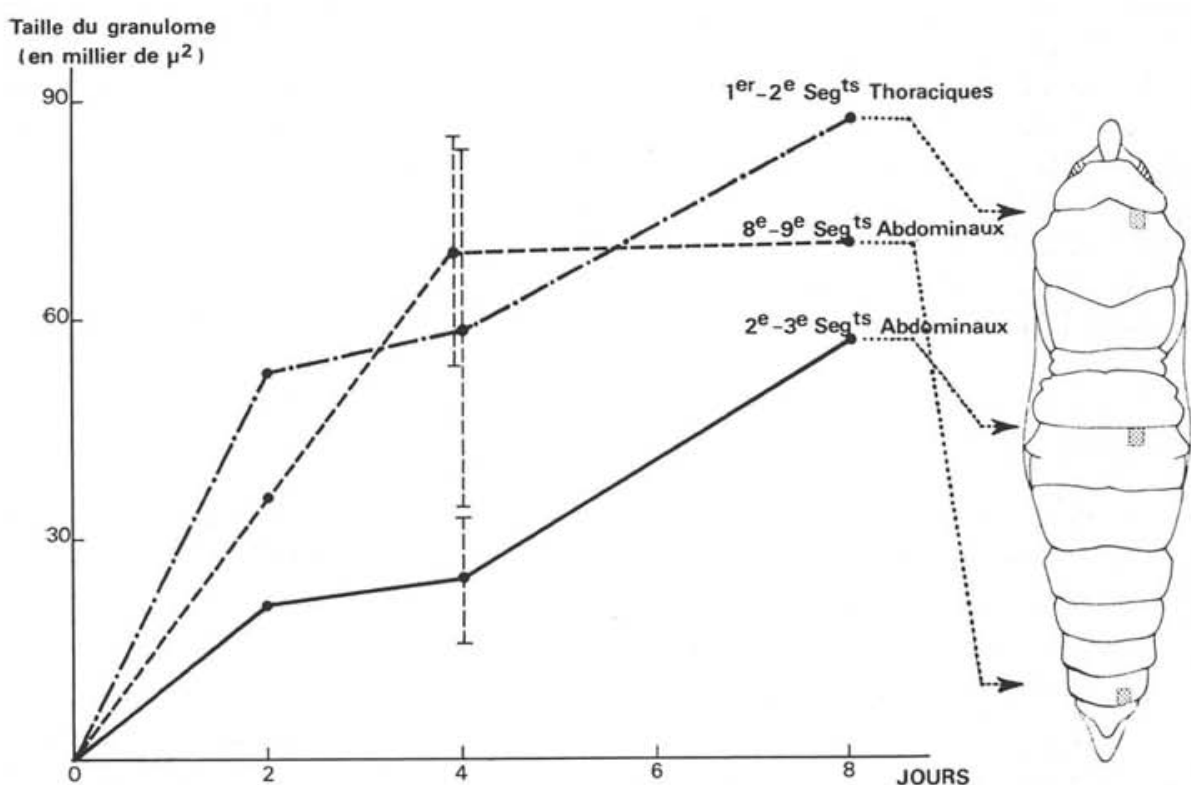

FIG. 1. - Variation de l'intensité de la réaction hémocytaire chez la chrysalide de Pieris en fonction du temps et de la région du corps (le schéma de la chrysalide permet de localiser avec précision les zones d'implantation du fil de nylon). 
capsule obtenue au niveau des deuxième-troisième segments abdominaux est nettement moins développée (la différence est statistiquement significative) que celles obtenues au niveau des régions distales; entre ces deux derniers sites, les niveaux réactionnels atteints sont très semblables. Dans les jours qui suivent la réaction hémocytaire se renforce de façon sensiblement égale pour les trois sites étudiés, les hémocytes continuent à se déposer. On notera toutefois que le dépôt hémocytaire reste toujours plus faible dans la région médiane de la chrysalide.

\section{Conclusions.}

Il s'avère donc que la capsule hémocytaire formée par la chrysalide de Pieris brassicae s'éloigne sensiblement du schéma classique. Cela tient sûrement au fait que la chrysalide en diapause est dans un état physiologique particulier. Toutefois, de telles capsules ont aussi été décrites chez d'autres espèces et ceci à différents stades de leur développement (Salt, 1956; Schacher et al., 1968).

En ce qui concerne l'évolution de l'intensité de la réaction dans les trois régions retenues, on note que l'intensité de la réaction dans la région médiane se maintient à un niveau plus faible que dans les deux régions distales; ceci est particulièrement net au cours des quatre premiers jours qui suivent l'implantation. Ces observations permettent peut-être d'expliquer les résultats obtenus avec Pimpla, hyménoptère parasite de la chrysalide de Pieris (Carton, 1973). Le taux de développement (nombre d'adultes pour 100 œufs déposés) de ce parasite est fonction de l'emplacement de ponte dans la chrysalide hôte: ce taux atteint $47 \%$ dans le cas où les œufs sont déposés dans la région des deuxième-troisième segments abdominaux; il n'atteint que $30 \%$ et $27 \%$ pour les régions correspondant aux premier-deuxième segments thoraciques et aux huitième-neuvième segments abdominaux.

\section{Bibliographie}

Brehelin (M.), Hoffmann (J. A.), Matz (G.) et Porte (A.), 1975. - Encapsulation of implanted foreign bodies by hemocytes in Locusta migratoria and Melolontha melolontha. Cell. Tiss. Res., 160, 283-289.

CARton (Y.), 1973. - Biologie de Pimpla instigator F. 1793 (Ichneumonidae, Pimplinae). II. Choix d'un emplacement privilégié dans l'hôte pour le dépôt des œufs ; mode de localisation. Entomophaga, 18, 25-39.

Carton (Y.), 1975. - Réactions hémocytaires chez la chrysalide des Lépidoptères. Intensité de la réaction en fonction de sa localisation chez Pieris brassicae. C.R. Acad. Sci., $281,579-582$.

Françors (J.), 1975. - L'encapsulation hémocytaire expérimentale chez le Lépisme Thermobia domestica. J. Insect Physiol., 2, 1535-1546.

SALT (G.), 1956. - Experimental studies in insect parasitism IX. The reactions of a stick Insect to an alien parasite. Proc. Roy. Soc., 146, 93-108. 
SALT (G.), 1970. - The cellular defence reactions of Insects. Cambridge University Press édit., Cambridge, 146 p.

Schacher (J. F.) et Khalil (G. M.), 1968. - Development of Foleyella philistinae Schacher and Khalil, 1967 (Nematoda ; Filarioidea) in Culex pipiens molestus with notes on pathology in the arthropod. J. Parasitol., 54, 869-878.

Snodgrass (R. E.), 1935, - Principles of Insect morphology. Mac Graw Hill, édit., New York, $66 \mathrm{p}$.

Walters (D. R.) et Williams (C. M.), 1968. - Reaggregation of Insect cells as studied by a new method of tissue and organ culture. Science, 153, 516-517. 